\title{
Resilience and Family Socialization Processes in Ethnic Minority Youth: Illuminating the Achievement-Health Paradox
}

\author{
Stacey N. Doan ${ }^{1} \cdot$ Stephanie H. Yu ${ }^{2} \cdot$ Blanche Wright $^{2} \cdot$ Joey Fung $^{3} \cdot$ Farzana Saleem $^{4} \cdot$ Anna S. Lau $^{2}$ \\ Accepted: 14 February 2022 / Published online: 24 February 2022 \\ (c) The Author(s), under exclusive licence to Springer Science+Business Media, LLC, part of Springer Nature 2022
}

\begin{abstract}
Youth in marginalized communities who "strive" to rise above adversity, including systemic racism and poverty, are considered "resilient." African-American, Latinx, and Asian-American youth often achieve admirable academic success despite limited social capital and high early life stress by adopting a "striving persistent behavioral style" (SPBS). SPBS may be supported by family socialization processes that facilitate reliance on self-regulation processes. Unfortunately, a young person's resilience in one domain (i.e., academic) can come at a cost in other domains, including physical and mental health morbidities that are under-identified and under-treated. Indeed, research suggests a link between SPBS in the face of adversity and later health morbidities among ethnic minority youth. Herein, we describe SPBS as an adaptation to minority stress that not only promotes social mobility but may also stoke physical and mental health disparities. We review how family processes related to academic, emotional, and ethnic-racial socialization can facilitate the striving persistent behavioral style. We emphasize the double bind that ethnic minority families are caught in and discuss directions for future research and clinical implications for individual and family-level interventions. While needed, we argue that individual and familylevel interventions represent a near-term work around. Solutions and factors that shape the need for SPBS and its cost must be addressed structurally.
\end{abstract}

Keywords Cost of competence $\cdot$ Resilience $\cdot$ Ethnic minority youth $\cdot$ Family socialization

Family socialization is the process by which children learn to acquire patterns of behavior that promote adaptation in their specific social context (Grusec \& Hastings, 2015). Among families, socialization processes across multiple domains, including academic (Hill, 2001), emotion (Hajal \& Paley, 2020), and ethnic-racial (Hughes et al., 2006), have been investigated. Bioecological systems theory (Bronfenbrenner, 1979) argues that an individual's development needs to consider multiple levels, including self, family, and society. Ethnic minority youth grow up within unique circumstances. They must learn to navigate social conditions that are often

Stacey N. Doan

stacey.doan@cmc.edu

1 Claremont Mckenna College and City of Hope National Medical Center, 880 N. Columbia Ave, Claremont, CA 91711, USA

2 University of California, Los Angeles, USA

3 Fuller School of Psychology, Fullerton, USA

4 Stanford University, Stanford, USA detrimental to their health and well-being, including racism, discrimination at individual and structural levels, acculturation demands, and migration-related stress (Coll \& Pachter, 2002). Thus, socialization practices in ethnic minority families are likely to differ significantly from White families, both in levels and kind, with implications for meaning and impact (Coll et al., 1996).

Herein, we review evidence for an understudied phenomenon in developmental science-the cost of resilience in ethnic minority youth and the role of family socialization practices. Some children growing up in disadvantaged contexts display remarkable resilience-defined as positive adaptation in the face of adversity (Luthar, 2006). A significant body of work suggests that self-regulatory processes, defined generally as modifying one's thoughts, emotions, and behaviors in the service of goal-relevant activities (Inzlicht et al., 2021), are powerful determinants of resilience (Moffitt et al., 2011). Importantly, self-regulation can also buffer the effects of adversity on outcomes (Troy \& Mauss, 2011). Relatedly, grit—defined as one's passion and perseverance towards long-term goals, has also been lauded as a 
factor that helps youth transcend adversity (Duckworth \& Gross, 2014). Grit has two components consisting of passion and perseverance of effort, with the latter overlapping conceptually and operationally with self-regulation (Muenks et al., 2017). These self-regulatory competencies lead to and help sustain high-effort coping and unwavering persistence towards one's goals. They can represent an adaptation to adversity, undergirding academic success, and economic mobility among disadvantaged ethnic minority youth. At the same time, however, this body of work fails to consider the context in which ethnic minority youth are developing. Persistence, high self-control, and intense efforts to cope in the context of oppression and chronic stress exposure can come at a cost. In the current paper, we characterize a "striving, persistent, behavioral style" (SPSB) as multidimensional, consisting of three components: motivational, affective, and behavioral factors. From a motivational perspective, these individuals may hold a prevention-focus orientation. Affectively, they are more likely to suppress emotions and distress. Finally, behaviorally, they are driven and high on persistence, which often may become unmodulated.
Importantly, we emphasized the ecological space in which SPSB may exert a health cost (see Fig. 1).

Individuals high in SPSB may be more likely to have a prevention-focused motivational orientation and high levels of self-control, which support expressive suppression and unmodulated persistence. Prevention-oriented individuals are driven by security, safety, responsibility, and avoidance of threat (as contrasted with promotion-focused individuals who are more concerned with advancement, ideals, and aspirations, and who have an approach orientation) (Higgins, 1998; Higgins \& Silberman, 1998). Individuals high on SPSB also exert high levels of self-control, which enable them to suppress negative emotions in the face of stress and persist through adversity. These characteristics confer benefits, including academic and career success. At the same time, resilience in one domain can come at a cost to another. Namely, the use of these strategies interact with the developmental context and, in certain situations, can lead to biological dysregulation with consequences for physical and psychological health. Central to our conceptualization of SPSB is the situational context. In contexts that lack social

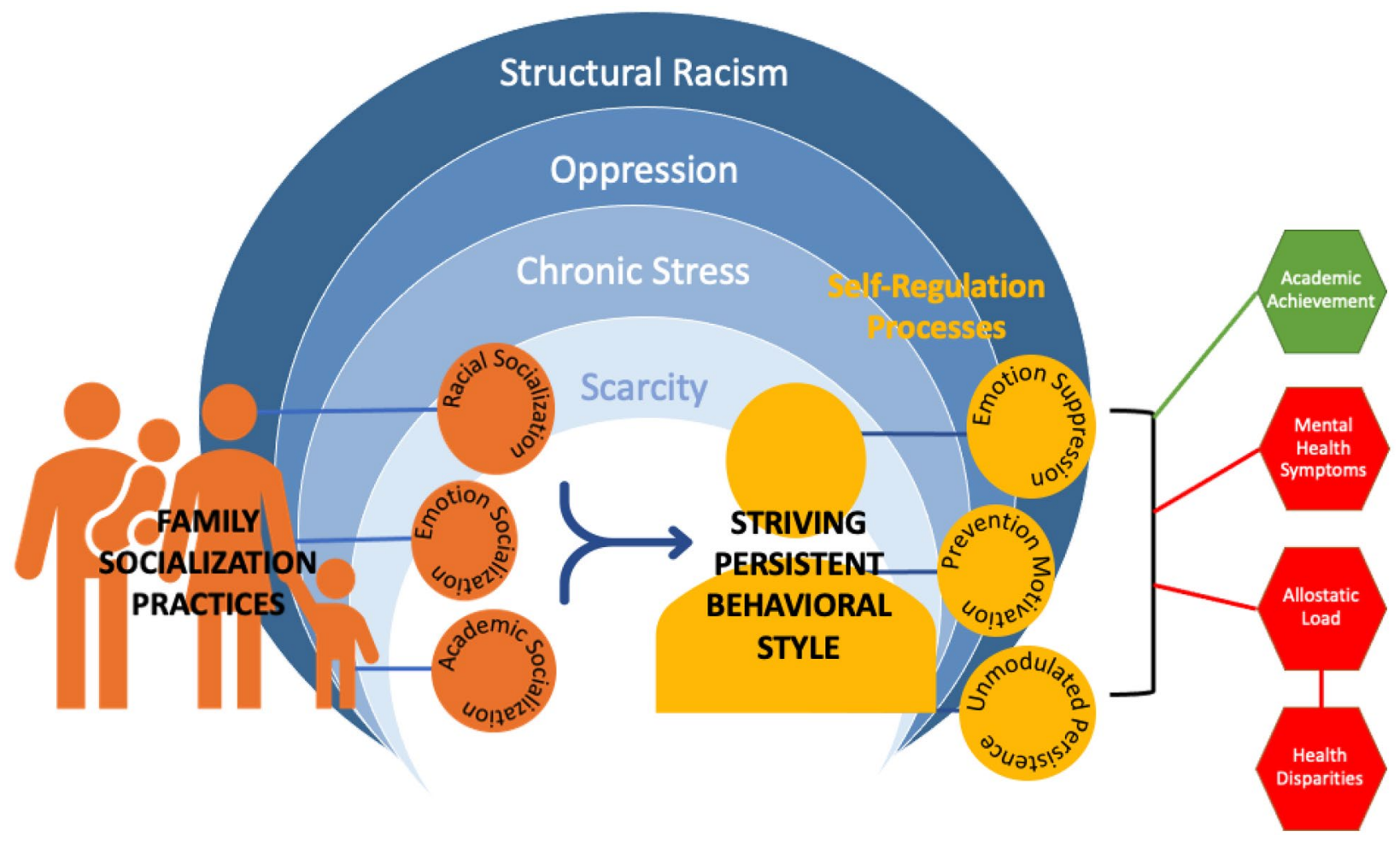

Fig. 1 Social Determinants, Family Socialization, and Self-Regulation Processes Contributing to Youth Striving Persistent Behavioral Style. Figure Caption. Socialization practices common in racial/ ethnic minority families are shaped not only by heritage cultural factors but also profoundly by socio-ecological demands and challenges associated with minority stress. Disproportionate exposure to adversity stemming from structural racism, oppression, chronic stress and scarcity evoke racial, emotional, and academic socialization practices that collectively can increase the likelihood of a Striving Persistent Behavioral Style in youth. This style is characterized by self-regulatory processes of emotion suppression, prevention motivation, and unmodulated perseverance. This approach to self-regulation can be adaptive in subserving the goal of promoting academic achievement, but may also be associated with costs, including internalizing mental health symptoms and the cumulative effects of heightened allostatic load that drive persistent racial disparities in health 
and structural support and are imbued by racism, oppression, and scarcity, SPSB in the long term is likely to fuel health disparities even among socially mobile racial/ethnic minoritized groups.

To illustrate, James (1994) argues that to maintain resilience and cope with threats of discrimination, African Americans have been found to rely on high-effort coping or John Henryism. John Henry was a character in Southern Black folklore, a steel-driving man with extraordinary physical strength and endurance who died after overworking himself. James argues that strategies that sustain cognitive and emotional engagement, driven by determination, commitment to hard work, and vigor (in our model conceptualized as unmodulated persistence), can lead to significant health consequences (James, 1994). Striving to succeed in the context of adversity can lead to profound health disparities driven jointly by the high stress and prolonged intensive effort to overcome the disadvantages of deeply entrenched systems of social and economic oppression among African Americans (James, 1994).

From a developmental perspective, these processes are likely influenced by family socialization practices, which, in turn, are adaptations to cumulative stress and disadvantage. We focus on academic, emotional, and racial socialization processes in the current review, given the robust body of literature in these areas and their conceptual links to SPSB. In the context of academic socialization, we highlight how socialization practices in ethnic minority families may take on a demanding, threat-based lens. Specifically, educational achievement and certain career options are seen as necessary to achieve safety and security, instead of an optional venue to fulfill an individual's aspirations and dreams. These socialization practices can then lead to a prevention focus in youth, heightening the emphasis on security and highlighting obligations. Emotion socialization practices may underscore the importance of expressive suppression and persistence, which may foster the development of a stoic emotional style, as well as unmodulated persistence. Racial socialization practices may amplify these messages by emphasizing the tensions and challenges of growing up as an ethnic minority in America and the importance of striving to succeed despite racism, oppression, and systemic discrimination.

Socialization practices that affect the development of SPSB are likely to begin early during the school-age years and culminate during the adolescent years. However, this style is expected to continue into adulthood, with consequences for job burnout and physical health. For many ethnic minority families, the advent of formal schooling is a critical juncture as education is promoted as essential for social mobility and, thus, likely to be heavily socialized. Adolescence is also a crucial period for identity development and educational attainment (Kramer, 1991). Due to wider social networks and increased cognitive abilities, adolescents may have increased experiences with racism and discrimination, awareness of stereotypes, and power differentials as a function of race (McKown, 2004; Quintana, 1998). It is also a time of significant biological changes and heightened emotional responses, which may exacerbate consequences for SPSB.

In the current paper, we take a multifaceted, contextlinked, and systems-oriented human development perspective (Spencer et al., 2006) to understand family socialization practices and the dialectic of resilience among ethnic minority youth. We argue that the narrative of individualized characteristics such as grit as the key to success amid adversity can be problematic for minoritized youth as the adversities they strive to overcome are considerable. Challenges such as race-based discrimination and prejudice, which White youth do not encounter, can result in racialized stress and trauma with biopsychosocial consequences that remain poorly understood (Saleem et al., 2016). Moreover, structural and institutional inequities may diminish the instrumental benefits of striving. This paper delineates how striving as a form of resilience may be shaped by family socialization practices driven by socio-ecological demands, culminating in some benefits but also short- and long-term costs. We end with recommendations for future research and implications for intervention and prevention.

\section{The Costs of Competence}

In a seminal paper, Luthar and colleagues (1993) argued that resilience is multifaceted and potentially costly, such that competence in one domain does not necessarily carry over to others. Indeed, a growing body of works suggests psychological, social, and physical health costs to resilience. In a predominantly African-American sample of adolescents, youth who displayed academic and social competence in the context of high adversity were more vulnerable to anxiety and depression symptoms than their similarly exposed peers without such competencies (e.g., Luthar, 1991). Compared to White students, AfricanAmerican and Native American youth who were academically successful also reported high social costs, operationalized as lower levels of social acceptance. The effect for African-American students was particularly pronounced in high-achieving schools, with smaller percentages of Black students (Fuller-Rowell \& Doan, 2010). Asian-American students in high-achieving schools reported higher levels of ethnic discrimination, perceived parental demand for perfectionism, internalized achievement pressures and lower levels of authenticity in everyday life (Luthar et al., 2021). Another study examined different profiles of youth engagement in school and linked these profiles to developmental outcomes. Findings suggest a class of 
youth who were high performing, but also emotionally disengaged; these youth also had the highest risk for mental health problems (Wang \& Peck, 2013). The authors argue that despite their competencies, the social and cultural context of the school may not foster belonging and emotional security. Consistent with stage-fit hypothesis, these data argue that interactions between the individual and the environment can exert unexpected influences on adjustment. (Eccles et al., 1993). Specifically, resilience is domain specific and that understanding resilience necessitates consideration of both individual characteristics, the larger ecological context, and their interactions with one another.

In addition to social and psychological costs, Brody and colleagues (2013) revealed a biological "cost of competence." Youth living in poverty who evidenced behavioral competence (i.e., academic achievement, social acceptance, self-control) also showed higher biological dysregulation (e.g., allostatic load) than their less competent peers. Among children raised in poverty, those with high selfcontrol were resilient in terms of lower rates of depression and substance use but showed accelerated cellular aging (Miller et al., 2015). Additionally, African-American adolescents from low-income families who displayed a striving behavioral style reported fewer depressive symptoms but higher rates of type 2 diabetes in adulthood than low-striving adolescents from similar backgrounds (Brody et al., 2016). Moreover, a recent study demonstrated that African-American youth who evince higher levels of selfcontrol had higher income, educational attainment, and mental health in adulthood (Chen et al., 2021a, 2021b). However, these same youth had higher adult insulin resistance, suggesting that achieving success in the face of racial inequities may come at a cost.

These data suggest that self-regulatory processes that drive resilience fail to confer health benefits for minoritized groups in the same way as it does for White majority groups (e.g., Brannon et al., 2017). For example, for some health outcomes (e.g., reproductive and birth outcomes), the social class gradient is reversed for African Americans. African-American individuals from lower social class ranks sometimes evince better outcomes than those from higher-class ranks (Williams et al., 2016). The benefits to physical health typically conferred by educational attainment are attenuated by ethnic minority status, with African Americans and Mexican Americans benefiting less (Fuller-Rowell et al., 2015; Seeman et al., 2008). Relatedly, among ethnic minorities, those high in socioeconomic status (SES) have comparable levels of the stress hormone cortisol to ethnic minorities from low SES backgrounds. In contrast, higher SES is related to lowered cortisol among Whites (O'Brien et al., 2013).

\section{Mechanisms Driving the Cost of Competence-Under the Skin and In the Air}

SPBS can amplify health costs through the physiological dysregulation that accumulates as youth adapt, despite chronic and recurrent stressors. Under stress, the hypothalamic-pituitary-adrenal (HPA) axis mobilizes the body to respond effectively to a stressor by initiating the "fight or flight" response. While adaptive in the short run, repeated activation of the system and consequently the prolonged exposure to stress hormones without adequate recovery results in "wear and tear" of the body called allostatic load, which is predictive of morbidity and mortality (Seeman et al., 2010).

In particular, self-regulatory processes that involve stoicism and emotion suppression and enable persistence through challenge may be pernicious contributors to allostatic load amid cumulative stress. Children low in emotionality and who also showed high persistence on an impossible puzzle task evinced higher allostatic load in late adolescence as compared to those who are more emotional (Doan et al., 2016). These findings support the hypothesis that high self-regulatory persistence combined with a stoic emotional profile may lead to chronic arousal of the nervous system and increased allostatic load conferring risk for health problems. Relatedly, emotion suppression leads to increased physiological and psychological stress-related reactions (Egloff et al., 2006), and in the context of risky environments, stoic children have higher levels of biological dysregulation as compared to their more emotionally expressive peers (Dich et al., 2017). In contrast, moderate expression of negative affect in the context of stress appears to confer biological protection, as indexed by immune (Moore et al., 2008) and cardiovascular (Dich et al., 2020) indices. Relatedly, externalizing behaviors also appear to protect youth against the effects of early adversity on biological dysregulation (Doan et al., 2019). Together, this implicates that high self-regulatory competencies have both benefits and costs.

Emerging evidence also indicates that the achievement of success or social mobility among ethnic minority youth may have a cascade of implications for adjustment related to shifting social contexts. As minoritized individuals attain increasing levels of success, they may encounter new minority-specific stress experiences. Social mobility may increase exposure to contexts where co-ethnic peers are underrepresented, race-related indignities are common, and performance pressure only increases to disprove racist stereotypes (Cole et al., 2003). Underrepresented minorities who overcome barriers to higher education and economic mobility appear to experience 
paradoxically negative health consequences mediated by racism-related stress. In a 33-year analysis of data from the National Longitudinal Survey of Youth, upwardly mobile African-American and Latinx adolescents went on to experience significantly more acute and chronic discrimination, respectively, than their socioeconomically stable counterparts (Colen et al., 2018).

\section{The Role of Family Socialization Processes}

In response to contextual demands, family socialization processes in ethnic minority communities may contribute to the development of SPBS in youth. In this section, we review socialization processes in three domains: academic, emotional, and ethnic-racial, and map them onto the motivational, affective, and behavioral components of SPBS. Note our review is not meant to be comprehensive, and we acknowledge the significant heterogeneity in experiences and identities within and between ethnic minority youth. At the same time, by providing a broad overview, we hope to lay out possible pathways between family socialization processes and SBSP that may be empirically tested.

\section{Academic Socialization}

Academic socialization involves the beliefs, values, and practices about education that parents engage in to foster children's educational aspirations and plans (Hill \& Tyson, 2009). Parental communication of their beliefs and values of education, as well as their involvement in school-based activities, must be understood in a cultural context as evidence suggests that academic socialization looks and functions differently among ethnic/racial and immigrant minority families (Ceballo et al., 2014; Reese et al., 1995; Yamamoto \& Holloway, 2010). In addition, while research has demonstrated that parental aspirations for children's educational attainment do not vary significantly across ethnic groups (Spera et al., 2009), ethnic minority caregivers often report more barriers to involvement (Rang, 2005; Waldfogel, 2006). Moreover, academic socialization usually occurs with ethnic-racial socialization (Cooper \& Smalls, 2010). Ethnic minority parents may emphasize the importance of education for social mobility and highlight pertinent obstacles such as racism and discrimination that may affect achievement and opportunity. These messages together can promote a prevention-focus motivational style to avoid failure and a tendency towards unmodulated persistence, marked by an unwavering focus on achievement demands even at times when personal well-being may be compromised.

Particularly salient to the promotion of SBSP is that for ethnic minority families, a core component of their communication is centralized around the idea that education is the sole avenue for social mobility with implications for both the individual and their families (Delgado-Gaitan \& Trueba, 1991). Studies have examined the relationship between cultural values, such as family obligation and academic socialization. For example, a sense of family obligation is more strongly related to academic values among Latinx and Asian-American adolescents than among Whites (Fuligni, 2001). While messages about the importance of education for a better life in the United States may result in a shared strong emphasis on education by parents and children (Suárez-Orozco \& Suárez-Orozco, 2001), it can foster a focus on responsibility and obligation. Moreover, messaging regarding sacrifices made by the family, as well as the necessity to be financially successful to support one's family, can motivate youth to succeed (Suizzo et al., 2016) but also lead to high-effort coping and unmodulated persistence (Cheung \& Pomerantz et al., 2011). At the same time, increased daily demands for instrumental assistance of the family (e.g., paid work, sibling care, housework) are linked to declining grades (Telzer \& Fuligni, 2009). While there appear to be connections between cultural values and academic socialization, particularly among immigrant ethnic minority families, the internalization of values by no means guarantees achievement outcomes.

There is some evidence for a positive relationship between academic socialization and achievement during early adolescence over and above parental involvement, with the strength of associations comparable across White and African-American youth (Hill \& Tyson, 2009). Academic socialization also appears to be negatively associated with depression for White and African-American youth (Wang \& Sheikh-Khalil, 2014). Parents' communication about education and future-oriented success appears most strongly related to mental health outcomes for adolescents from low SES backgrounds (Wang et al., 2014). Messages and supportive communication about school, the importance of delaying gratification, and considering future plans and goals may foster academic self-efficacy and reduce feelings of helplessness. At the same time, however, in contexts where youth have few resources to succeed and are subject to discrimination and stereotypes, socialization processes that urge high achievement, individual effort, and underscore the threats of failure can stoke pressure and distress.

Indeed, other research reveals emotional costs when academic socialization imparts high pressure to succeed. A growing literature describes this strain for Asian-American youth in the college preparatory context. For example, in a qualitative study, Korean American adolescents reported feeling pressured to excel by their parents and fearing their parents' disappointment if they did not do well academically (Choi \& Dancy, 2009). For Asian-American youth, research has also documented the harmful effects of the model minority stereotype that Asian Americans are built for academic 
superiority due to diligence and talent (Yoo et al., 2010). Among Asian-American students attending schools with high Asian enrollment, internalizing the model minority myth of unlimited ability to achieve upward mobility was linked to anxiety and depression (Atkin et al., 2018). Communicated expectations that emphasizes getting good grades or college admission (e.g., attaining entrance to elite universities or receiving prestigious scholarships) are described as heavy generational burdens by Asian-American youth (Yang $\&$ Rettig, 2003). Once in college, Asian-American youth also report the highest level of feelings of imposter syndrome, which in turn, significantly predicted mental health (Cokley et al., 2013).

Finally, some researchers have argued that for African-American students, achievement may lead to social realms where they feel alienated, rejected, and disconnected (Ford, 1993). They may also be at an increased risk for peer rejection, as they may be perceived as "acting White" (Fordham, 1988). Stereotypes around achievement and the burden of possibly confirming these negative stereotypes can undermine performance. At the same time, they lead to feelings that the individual must work harder to not confirm the stereotype (Steele, 2011). Among Latinx youth, researchers have argued that cultural values may conflict with the educational environment of US schools (La Roche \& Shriberg, 2004), leading researchers to emphasize the importance of the learning environment for Latinx youth's academic achievement (Wilkins \& Kuperminc, 2010).

In sum, academic socialization practices among ethnic minority families can be central to academic success. Ethnic minority parents often view higher education as the singular mechanism to safeguard economic opportunity amid a racial hierarchy that privileges the White majority (Louie, 2004). While achievement focus is considered a positive adaptation, certain conditions may render minoritized youth vulnerable. Ethnic minority parents may socialize ideas such as educational attainment is a necessity, that family well-being is dependent on the child's success, and that the youth must strive hard to overcome negative stereotypes. These messages may result in greater achievement-related stress (Yoo et al., 2015) and depressive symptoms (Atkin et al., 2018). In the ecological context of their lived experiences, these socialization practices can foster both an unmodulated persistence and a prevention-focus style that lead youth to try and succeed at all costs. Pressures to succeed in the context of significant challenges may lead to adaptive outcomes, including educational attainment, but incur potential emotional and health costs.

\section{Emotional Socialization}

Family emotion socialization practices facilitate emotional development by helping children understand, communicate, and effectively regulate their emotions (Eisenberg et al., 1998). Researchers have described "supportive" emotion socialization practices as ones that comfort, elaborate, and clarify, or problem-solve when children are sad or angry, whereas "non-supportive" emotion socialization practices are defined as those that minimize, punish, or ignore children's negative emotions (Eisenberg et al., 1996). Data suggest that supportive emotion socialization is linked to greater social competence and fewer externalizing problems, yet this research has primarily been conducted with White middle-class families. (e.g., Eisenberg et al., 1996; Morris et al., 2007). Socialization practices and their effects are likely to be affected by cultural norms and the need to protect children from discrimination (e.g., Nelson et al., 2012a, 2012b). The implications of parental emotion socialization practices need to be understood through the lens of contextual demands faced by groups with minority status experiences of racism, discrimination, and acculturation stress, as well as meanings shaped by enculturation within heritage cultures (Coll \& Pachter, 2002; Coll et al., 1996).

Studies have found so-called "non-supportive" emotion socialization to be more normative in African-American families (Montague et al., 2003). African-American mothers, especially of boys, were more likely than White mothers to punish and minimize displays of negative emotion (Nelson et al., 2012a, 2012b). African Americans are more likely than Whites to retrospectively report that their parents downplayed or punished their expression of negative feelings (Leerkes \& Siepak, 2006; Montague et al., 2003). Given the legacy of racism and slavery, teaching African-American children, particularly boys, to downregulate displays of negative emotion is adaptive based on continued threats to personal safety due to over-policing and violence (Dunbar et al., 2015; Nelson et al., 2012a, 2012b). African-American caregivers may use supportive practices to teach children emotion regulation skills, but also disciplinary practices to socialize them to suppress negative affect because such expression may be dangerous in racially biased situations (Garrett-Peters et al., 2011).

The correlates and effects of emotion socialization practices differ across African-American and White families. African Americans retrospectively reported feeling more loved and less hurt or ashamed when their parents engaged in punitive and minimizing practices than White respondents (Perry et al., 2017). In African-American families, maternal punitive and minimizing reactions to children's negative emotions have been linked to lower peer aggression (Smith \& Walden, 2001), whereas encouraging expression of negative emotions was associated with less competent 
peer interactions (Nelson et al., 2013). Parenting practices that minimize emotion display may facilitate expressive suppression and stoicism and enable a striving persistent behavioral style.

Compared to White mothers, Latina mothers also appear more likely to minimize or ignore their children's expressions of negative affect (Lugo-Candelas et al., 2015). Socialization practices in Latinx families may be shaped by respeto, which emphasizes the importance of child deference and proper demeanor (Harwood et al., 1995), and its cultivation may involve forms of emotion socialization classified as non-supportive with less emphasis on elaboration, reflection, and exploration of child emotion (Durik et al., 2006). Compared to White mothers, Mexican American mothers talked less about the causes and consequences of emotions to their preschool children (Eisenberg, 1999). Significantly, the implications of emotion socialization practices observed in White families may not generalize to families of color. "Non-supportive" parental responses were unrelated to children's emotion knowledge in a sample of Mexican and Dominican immigrant families (Pintar Breen et al., 2018) and not linked to mental health outcomes for Latinx adolescents (Lugo-Candelas et al., 2016). Parental responses that minimize or discourage the expression of negative affect may not be perceived by youth as unsupportive when they are consistent with broader organizing values understood in families. Responses to children's emotions reflect culturally normative processes designed to help youth modulate their affect to serve broader socialization goals, as discussed below.

Asian populations often characterized as interdependent have been described as particularly focused on interpersonal sensitivity and emotional restraint (Friedlmeier et al., 2011; Tsai et al., 2007), which may in turn shape emotion socialization practices. Moreover, the model minority myth applied to stereotype Asian Americans may also promote assimilation and conformity to silence (Omadeke, 2021). In their emotion socialization practices, Asian parents may de-emphasize ego-focused emotions (e.g., anger, pride, disappointment), which are considered threatening to harmony. Parents may instead attune children to other-focused emotions, which are instrumental for moral awareness and attunement to social rules, such as shame (Fung, 1999) and empathy (Chan et al., 2009).

Asian parents engage in emotion socialization practices that emphasize stoicism and self-control. Chinese parents are less likely to talk about internal psychological states and more often about behaviors (Doan \& Wang, 2010). Hong Kong Chinese parents were more likely to dismiss and minimize children's expressions of emotions (Chan et al., 2009). Nepalese caregivers often respond to children's displays of anger by conveying disapproval (Cole et al., 2006). Indian mothers consider the expression of hurt emotions as less acceptable than expressions of physical pain and convey to children that it is unacceptable to express sadness or anger (Raval \& Martini, 2009). Compared to White mothers, Indian American immigrant mothers were more likely to report responding non-supportively (by Western standards) to their children's display of sadness or anger (McCord \& Raval, 2016).

While the focus on behavior rather than emotional states appears to have some consequence on emotion understanding (Doan \& Wang, 2010), it may promote higher levels of behavioral control. Other studies have reported adverse effects of such "non-supportive" practices to be attenuated in Asian cultural contexts. For example, mothers' nonsupportive responses were unrelated to child outcomes for Indian immigrant families but positively associated with child behavior problems in White families (McCord \& Raval, 2016). In a Chinese sample, parental minimizing of child emotion had no significant link to behavioral problems or social competence (Tao et al., 2010). Other studies report no differences in supportive emotion practices, but Chinese immigrant mothers report higher levels of unsupportive practices-further, the negative impact of unsupportive practices on behavioral problems was only significant for White but not Chinese immigrant children (Yang et al., 2020). Finally, emotion awareness appears to be associated with increased behavioral problems in Chinese immigrant children (Doan \& Wang, 2018).

In summary, emotion socialization practices that encourage the downregulation of emotion expression appear common among racial/ethnic minority families. These practices represent an adaptive response to ecological conditions associated with minority stress and fear of discriminatory treatment. They may also be consonant with interdependent cultural values and ethnotheories of optimal child development. There is also evidence that parenting practices that involve the minimization or discouragement of emotion expression may not have the same implications for the development of social competence or behavioral problems. Thus, these emotion socialization practices have specific adaptive functions in the ecological contexts of ethnic minority youth. At the same time, these practices appear to contribute to greater reliance on emotion suppression coping, which can be linked to internalizing symptoms and interpersonal costs, even among ethnic minority youth (Lau et al., 2009; Tsai et al., 2017). Emotion suppression represents a component of self-regulation that facilitates the SPBS.

\section{Ethnic-Racial Socialization}

Racially/ethnically marginalized youth face the taxing demand of learning how to manage experiences of systemic and personal discrimination (Cave et al., 2020). A critical avenue through which minoritized youth learn to navigate 
racism is family ethnic-racial socialization (ERS), often defined as parents' transmission of "information, values, and perspectives about ethnicity and race to their children" (Hughes et al., 2006, p. 747). Research has examined messages families convey to children about their racial or ethnic group, including those related to discrimination and racial inequality, and the ensuing impacts on child development (Simon, 2021; Umaña-Taylor \& Hill, 2020).

There are four commonly studied ERS message types (Hughes et al., 2006). Cultural socialization is defined as the practices by which families teach their children about their culture, both explicitly or implicitly promoting cultural customs, traditions, and pride towards their racial or ethnic group. Preparation for bias involves families' efforts to foster their child's awareness of racism and prepare them to cope with and respond to it. Egalitarianism messages often minimize race and racial differences and instead emphasize individual qualities. Finally, promotion of mistrust consists of families' messages or practices that encourage wariness, caution, or distrust towards members outside of their ethnic-racial group. ERS processes influence ethnic identity development, adjustment outcomes, and responses to discrimination experiences across ethnic-racial groups (Ayón et al., 2020; Evans et al., 2012; Woo et al., 2020). How and when ERS is linked to positive or negative outcomes often varies by contextual factors, the type of ERS assessed, and is likely shaped by the unique historical racialized experiences of different groups (Lambert et al., 2021; Liu \& Lau, 2013; Priest et al., 2014; Simon, 2021). While ERS practices are necessary for the well-being and survival of racial/ethnic minority youth, SPBS may emerge in racially marginalized youth who internalize messages focused on the need to work harder than White youth to overcome structural barriers to success (Lesane-Brown, 2006).

Early research on ERS has primarily focused on AfricanAmerican families (Hughes et al., 2006; Simon, 2021). Studies suggest that ERS in African-American families focuses on promoting youth's racial pride and self-esteem despite prevailing systems of oppression (Simon, 2021) and preparing youth for racial bias and systemic barriers they will face (Evans et al., 2012). For example, many African-American caregivers teach their children how to manage and survive police encounters; such messages are critical for safeguarding youth (Anderson \& Stevenson, 2019). Empirical findings indicate that racial pride messages and some messages focused on preparing for and coping with discrimination are associated with higher resilience and adjustment in AfricanAmerican youth and young adults (Brown, 2008; Kyere \& Huguley, 2020). They also appear to be protective, buffering the effects of discrimination on academic achievement (Banerjee et al., 2018; Neblett et al., 2008). However, there are mixed findings regarding messages that focus on race and mistrust. For example, other studies show that some messages focused on racism and mistrust are associated with adverse adjustment outcomes (Kyere \& Huguley, 2020; Lambert et al., 2021; Liu \& Lau, 2013).

Some ERS messages may cultivate the view that stressful experiences, including discrimination, can be altered by hard work (Geronimus \& Thompson, 2004), a view that may be linked to maladaptive perfectionism in African-American youth (Lambert et al., 2014). Increased goal-striving stress, or the perceived gap between one's aspirations and anticipation of likely success, has been associated with high-effort coping, neuroendocrine stress hormones, and blood pressure in African-American adults (DeAngelis, 2020). Prolonged high-effort coping coupled with chronic stress damages mental and physical health among African Americans (Bennett et al., 2004; Cole \& Omari, 2003; Hudson et al., 2015). Thus, although ERS messages encourage adaptation and academic resilience for African-American youth to overcome barriers, a resultant SPBS potentiates an array of health costs.

A smaller but growing body of research examines ERS processes in Latinx families (Ayón et al., 2020). Cultural socialization practices in Latinx families have been posited to focus on youth's retention of their heritage culture and history (i.e., promoting language retention, eating ethnic foods, celebrating cultural and religious holidays) and cultivating family values such as familismo and respeto, emphases on a strong work ethic, and promotion of positive ethnic identity development (Aldoney \& Cabrera, 2016; Ayón et al., 2020). Cultural socialization has been primarily linked to positive outcomes in Latinx youth, including ethnic identity development (Umaña-Taylor et al., 2014), ethnic pride, belonging (Hernández et al., 2014), and psychological well-being (Espinoza et al., 2016; Liu \& Lau, 2013). However, preparation for bias and promotion of mistrust has been studied less frequently in Latinx families than cultural socialization. These practices may be less common, with promotion of mistrust used the least frequently (Grindal \& Nieri, 2015). Preparation for bias may be critical for Latinx youth in the context of increasing discrimination experiences related to rising anti-immigrant rhetoric and policy and precarity in communities with mixed documentation status (Cross et al., 2020, 2021). However, findings are mixed with respect to adjustment correlates of preparation for bias.

Cultural socialization has been strongly linked to family obligation values and family assistance behaviors in supportive Latinx families (Tsai et al., 2015). Family obligation values and family assistance behaviors, such as sibling care, translation/cultural brokering, and household chores, relate to improved well-being and a greater sense of connection to the family in Latinx youth (Telzer et al., 2014, 2015). However, it may also be linked to SPBS. Latinx youth who carry high burdens of family assistance can suffer adverse outcomes (Burton, 2007), particularly when necessitated by 
parental physical and mental health (Telzer et al., 2015). Racial socialization messages from caregivers that highlight conditions of prejudice prompt African-American, Latinx, and Asian-American youth to employ a coping strategy of gearing up to disprove negative stereotypes (Phinney \& Chavira, 1995). This focus may also lead to a preventionfocus orientation where responsibility and security are emphasized. Latinx youth describe a drive to achieve, refute stereotypes and uplift their communities (Foxen \& NCLR, 2010). Simultaneous achievement motivations to support family and disprove negative stereotypes are adaptive in Latinx youth yet may confer both costs and benefits.

Similar to Latinx families, Asian-American cultural socialization practices are thought to focus on maintenance of heritage culture, management of acculturation to the majority culture, and development of a positive ethnic identity (Juang et al., 2016; Kim et al., 2018). Cultural socialization has been linked to positive adjustment outcomes, including racial/ethnic identity development (Nguyen et al., 2015; Xie et al., 2021). It has been suggested that AsianAmerican families are less likely to engage in preparation for bias or promotion of mistrust, which may result in underdeveloped skills for coping with discrimination and identity threat (Wang et al., 2020). These practices are thought to assist youth in dealing with experiences of interpersonal and structural discrimination (Juang et al., 2016), a historical necessity compounded by renewed anti-Asian sentiment and violence arising from the COVID-19 pandemic (Cheah et al., 2020).

Findings related to adjustment outcomes for both processes are mixed, although conclusions are limited by the paucity of studies. For example, preparation for bias has been linked to greater ethnic identity, exploration, and engagement (Woo et al., 2020), but also to higher levels of pessimism and, in turn, depression (Liu \& Lau, 2013), feelings of cultural misfit (Benner \& Kim, 2009), and lower public regard (Rivas-Drake et al., 2016) in Asian-American youth and young adults. Meanwhile, promotion of mistrust has been associated with higher self-esteem (Gartner et al., 2014) and ethnic identity (Woo et al., 2020), but lower social competence (Tran \& Lee, 2010), and ethnic identity for immigrant Asian-American youth (Gartner et al., 2014). Promotion of mistrust was also found to buffer the relations between microaggressions and self-esteem and private regard in one study of Asian-American young adults (Thai et al., 2017) but exacerbate the discrimination-distress link for Asian-American adolescents in another (Atkin et al., 2019).

Similar to Latinx families, socialized family obligation values and family assistance behaviors have been associated with positive well-being outcomes for Asian-American youth (Juang \& Cookston, 2009; Telzer \& Fuligni, 2009), but higher internalizing symptoms in some contexts (Telzer
\& Fuligni, 2009). Indeed, one study of South Asian-American young adults found that cultural socialization was positively associated with model minority pride, pressure, and achievement orientation, while preparation for bias and promotion of mistrust were positively related to model minority pressure and adjustment problems (Daga \& Raval, 2018). For Asian-American youth, a potent constellation of family obligation, racialization messages, and internalization of the model minority stereotype may conspire to shape the SPBS marked by achievement pressure, unmodulated persistence, and high-effort coping amid stress.

ERS practices help ethnic minority youth prepare for the challenges they will inevitably encounter across their development. Socialization messages focus both on preparing and coping with discrimination and other forms of oppression, as well as cultural values and beliefs that foster effective strategies and develop protective identities. They are both a reaction to the larger social-cultural environment in which parents are raising their children, as well as a reflection of their identity and heritage. At the same time, these messages, while fostering resilience in one domain, may have unintended consequences, particularly as children become increasingly involved in a larger society that may not reflect, support, or acknowledge their lived experiences. Cultural values may clash with societal norms. Systemic discrimination may derail and neutralize individual efforts to excel in institutions marked by structures that perpetuate inequity. As ethnic minority youth struggle to achieve in these contexts, they may achieve short-term benefits and potential long-term social, emotional, and health costs.

\section{Discussion}

In the current paper, we raise the issue of resilience among high-achieving ethnic minority youth and argue that certain patterns of behaviors, namely self-regulatory competencies, and persistence, which have been traditionally associated with positive adaptation, can come at a health cost. In particular, we emphasize the importance of understanding these behaviors and the antecedent socialization practices engaged by parents that may lead to higher levels of a striving, persistent behavioral style (SPSB). Notably, we argue that these socialization practices are adaptations to highstress, high-risk environments, environments in which ethnic minority youth are disproportionately represented. SPSB is undeniably a positive adaptation that supports academic and career success. However, we problematize the idea that they are cost free. Overall, a societal focus that prizes individuallevel characteristics such as self-regulation and grit, engenders a "victim-blaming" perspective to explain achievement gaps that can be attributed to individual and group deficits 
rather than structural inequities (Golden, 2017; Tewell, 2020).

Rather, we argue for the importance of a "critical bifocality" (Weiss \& Fine, 2012) where individuals must be understood as a product of their social and cultural milieu, and that inequality gaps have profound impacts on youth's behavior and their consequences, both positive and negative. Weiss and Fine argue that we need to "make visible the sinewy linkages ...through which structural conditions are enacted... and the way to which such conditions come to be woven into community relationships and metabolized by individuals" (Weiss \& Fine, 2012, p. 174). As we discuss later, we believe that in considering resilience, it is imperative that stakeholders focus not only on the benefits of certain behavior styles but potential consequences as well. Moreover, while consideration of individual-level interventions is critical, system and institutional reforms that dismantle the structural conditions that require ethnic minority students to adopt a SPSB to "work twice as hard to get half as far" is needed. Yet as we progress toward structural reform, there is a place for individual-level interventions that target the self-regulatory aspects of SPSB, including expressive suppression and unmodulated persistence that may be most proximally related to adverse physical and mental health outcomes. Below we lay out directions for future research and conclude with implications for intervention and prevention research.

\section{Directions for Future Research}

While there is a growing body of research demonstrating the costs of competence (for a review Chen et al., 2021a, 2021b), to date, few studies have examined the specific mechanisms that may be driving these effects, as well as individual or contextual factors that may mitigate or exacerbate these costs. Understanding the factors that link SPSB to health outcomes would provide further evidence for our model and identify targets for intervention. To illustrate, if expressive suppression is indeed a core component as depicted in our model, emotion-based interventions that foster more adaptive emotion regulatory coping skills could potentially mitigate the impact of SPSB. In addition, future studies should take a lifespan approach that would help us identify how SPSB may manifest across development and identify periods of vulnerability and opportunity.

In the current paper, we focus on issues of oppression and challenges associated with living as an ethnic minority in the US; challenges which in some ways transcend boundaries of race/ethnicity. At the same time, it is essential to note that there is significant heterogeneity within ethnic minority youth in the United States, including differences in country of origin, immigration and documentation status, language, racial phenotype, socioeconomic status, and ethnic composition of schools and neighborhoods in which they live. Moreover, these identities overlap, leading to lived intersectional experiences that are more than the sum of their parts. These experiences are likely to interact in complex ways with socialization practices, their relations to SPBS, and the potential consequences of SPBS itself. We expect these factors to mitigate or exacerbate relations among family socialization practices, SPBS, and the consequences of SPBS on health. For example, we expect that SPBS exacts the most significant physical and emotional health costs for ethnic minority youth in neighborhoods with higher levels of exposure to structural and interpersonal racism, in contexts with intense competition for educational opportunity (e.g., selective college admissions, programs designed to weed out students), and within predominantly White institutions.

In this review, we delineate different components of socialization and discuss how we think that they may promote various facets of SPSB. At the same time, just as individuals exist as part of the fabric of the larger social and cultural contexts, socialization practices do not exist in isolation. While the extant literature tends to treat academic, emotional, and racial socialization as distinct, in reality, they are likely to interact with one another. To illustrate, in discussing African-American families, researchers have argued that emotion and ethnic-racial socialization practices are likely to be integrally intertwined as when emotion socialization may be used to prepare children for bias (Dunbar et al., 2017). Thus, research that examines the extent to which these practices interact and how together they may have synergistic and novel effects is very much needed.

Finally, given space constraints and the focus on the existing literature, our review focuses very narrowly on a subset of ethnic minority youth. It does not consider the experiences of other racial/ethnic groups in America, including Indigenous youth (American Indian, Native Hawaiian, Alaskan Native), Pacific Islanders, and youth of Arab and Middle Eastern, and North African (AMENA) descent. To date, there is little basic research on socialization practices among these groups. Undoubtedly, there will be variation in lived experiences, and consequently, the extent to which our model is generalizable.

\section{Implications for Intervention and Prevention Efforts}

Based on the current state of the literature, we offer some clinical implications. First, raising awareness of the costs associated with being a high-achieving student of color in high-risk contexts may prompt parent behavior that supports child well-being. We do not suggest that self-regulation competencies, including perseverance and high-effort coping, should be avoided. They are essential for successful adaptation. Instead, psychoeducation can highlight the diminishing returns of sustained unrelenting high-effort 
coping while emphasizing the importance of self-care practices and the essential nature of health behaviors for physical and mental health. In particular, parental knowledge about the costs of resilience may counteract relational processes that foment pressures to achieve that can escalate within the context of interdependence-oriented families living with socioeconomic disadvantage. Beyond awareness raising, specific interventions may offset risks through skill building that target the proximal mechanisms likely responsible for the ill health effects of SBPS.

\section{Mindfulness Interventions}

Mindfulness is a form of attention training in which one learns to pay attention to the present moment without judgment (Kabat-Zinn, 2003). With extended practice, the mind is trained to be less reactive and more regulated. Mindfulness training may engage healthy emotion regulation strategies in the face of racialized stress to reduce emotion suppression and experiential avoidance (Metz et al., 2013), two putative mechanisms underlying risks of the SPBS. First, mindfulness emphasizes non-judgmental awareness and healthy engagement with emotions to experience rather than suppress them (Hayes \& Feldman, 2004). Likewise, mindfulness increases emotion acceptance to limit attempts to disengage from unpleasant internal states (Greco et al., 2011; Lindsay et al., 2018). Although avoidance temporarily provides relief, it tends to result in rebound of prolonged negative affect (Aldao et al., 2010). Mindfulness interventions reduced youth internalizing symptoms and stress in Asian-American and Latinx students, mediated by reductions in emotion suppression and rumination (Fung et al., 2019). Furthermore, mindfulness meditation may modulate neurobiological mechanisms of chronic stress, such as telomere regulation (Conklin et al., 2019), immune system functioning (Black \& Slavich, 2016), and cortisol secretion (Sanada et al., 2016).

\section{Ethnic-Racial Socialization Interventions}

Structured ERS interventions can provide caregivers with ways to discuss structural racism while encouraging coping skills that enhance self-care and resistance, rather than reliance on maladaptive sustained high-effort coping and emotion suppression. For example, Anderson et al. (2019) developed Engaging, Managing, and Bonding through Race (EMBRace), a family racial socialization intervention that aims to address racial trauma in African-American families while bolstering family bonds and use of emotion-focused coping strategies. Such interventions that support raceaffirming and preemptive, rather than reactive ERS practices alongside racial coping self-efficacy may reduce the health costs associated with SPBS. Indeed, research suggests that certain ERS messages encouraging close familial relationships and collectivism were linked to lower use of prolonged, active high-effort coping (i.e., John Henryism) in African-American young adults (Blackmon et al., 2016).

\section{Collective Healing and Action}

It is possible that interventions promoting collective and community healing-moving beyond individual-level approaches to coping-may also mitigate the negative health and mental health risks of SPBS for minoritized youth. French et al. (2020) proposed a framework for radical healing, which engages components of collectivism, critical consciousness, radical hope, strength and resistance, and cultural authenticity and self-knowledge to cope with racial trauma. Aspects of radical healing that encourage group resistance and activism can offer tangible opportunities to resist structures of oppression rather than engage in unrelenting persistence to achieve limited gains within these structures. Meanwhile, collective coping with racial trauma can reduce emotional stoicism, expressive suppression, and experiential avoidance by encouraging support-seeking, belongingness, and connection to one's group. Racially attuned collective coping that includes approach-oriented strategies, such as collective action, intergroup coalition, and civic engagement appears to buffer the negative mental health effects of racial discrimination (Jones et al., 2020; Mekawi et al., 2021).

\section{Structural Interventions}

Finally, there is a dire need for antiracist structural interventions to reduce systemic inequities that place racially/ ethnically marginalized youth at greater risk of health and mental health morbidities and environmental demands for a SPBS. A focus on individual-level interventions rather than structural change continues to place the onus on oppressed groups to overcome the adverse conditions they are subjected to. Structural interventions should include redistribution of resources and dismantling systems that drive disparities. For example, school funding systems perpetuate inequity when there is reliance on property taxes that keep resources concentrated in affluent neighborhoods and starve schools serving low-income families. Standardized testing admissions requirements serve a gatekeeping role presenting barriers to high education (Cunningham, 2019). School systems with long observed disparities in discipline that disproportionately punish African-American and Latinx students contribute to the school-to-prison pipeline rather than situating schools as the engine of social mobility (Ayón et al., 2014). Racial bias in the processes used to identify the "gifted and talented" steal opportunity from racial/ethnic minority youth (McBee, 2010). Corrective and affirmative 
actions are needed. Implementation of equity scorecards at all levels of education can identify areas of racial inequity and assess the effectiveness of initiatives that aim to foster institutional change to eliminate racial disparities for students (Harris III \& Bensimon, 2007). Progressive public policy analysis and reform are needed to manifest enduring structural changes to remove the burdens that demand unrelenting persistence for youth of color to get only half as far.

Parents are invested in the well-being of their children. Socialization practices among ethnic minority parents are designed to inculcate the beliefs, values, and skills that will promote the successful adaptation of their children. This socialization often occurs as a reaction to systemic oppression and scarcity. While SPSB can lead to adaptive achievement and mobility outcomes, there may be a cost to the high-effort coping and dysregulated persistence in the face of the structural challenges that ethnic minority youth encounter. Moreover, the rhetoric on grit and self-regulation gives way to a deficit-focused lens that explains persistent group disparities to aggregated individual-level shortcomings (Tewell, 2020). The focus on bootstrap rhetoric that points to individual characteristics of self-control and grit as cornerstones of success shifts the focus away from structures and social determinants and makes it necessary for disadvantaged youth to cultivate SPBS. Much research is needed to understand the impact of these socialization practices on both positive and negative adaptation. In this review, we highlight and problematize the narrative of grit and higheffort coping as solutions to problems of oppression and poverty. We lay out pathways by which socialization practices may lead to SPSB, perpetuating health disparities even among socially mobile ethnic minority individuals. In doing so, we hope to inspire further research in this arena to aid in intervention and prevention efforts that may improve the lives of racial/ethnic marginalized youth.

Funding This project was funded in part from an NIMH grant R01-MH128729 to PI Lau and NSF grant NSF BCS 2043078 to PI Doan.

Data Availability Not applicable.

Material Availability Not applicable.

\section{Compliance with Ethical Standards}

Conflict of interest None of the authors have any conflict of interest to declare.
Ethical Approval Not applicable.

Consent to Participate Not applicable.

Consent for Publication Not applicable.

\section{References}

Aldao, A., Nolen-Hoeksema, S., \& Schweizer, S. (2010). Emotionregulation strategies across psychopathology: A meta-analytic review. Clinical Psychology Review, 30(2), 217-237. https://doi. org/10.1016/j.cpr.2009.11.004

Aldoney, D., \& Cabrera, N. J. (2016). Raising American citizens: Socialization goals of low-income immigrant Latino mothers and fathers of young children. Journal of Child and Family Studies, 25(12), 3607-3618. https://doi.org/10.1007/s10826-016-0510-x

Anderson, R. E., McKenny, M. C., \& Stevenson, H. C. (2019). EMBRace: Developing a racial socialization intervention to reduce racial stress and enhance racial coping among Black parents and adolescents. Family Process, 58(1), 53-67. https://doi. org/10.1111/famp. 12412

Atkin, A. L., Yoo, H. C., Jager, J., \& Yeh, C. J. (2018). Internalization of the model minority myth, school racial composition, and psychological distress among Asian American adolescents. Asian American Journal of Psychology, 9(2), 108-116. https://doi.org/ 10.1037/aap0000096

Atkin, A. L., Yoo, H. C., \& Yeh, C. J. (2019). What types of racial messages protect Asian American adolescents from discrimination? A latent interaction model. Journal of Counseling Psychology, 66(2), 247-254. https://doi.org/10.1037/cou0000297

Ayón, C., Nieri, T., \& Ruano, E. (2020). Ethnic-racial socialization among Latinx families: A systematic review of the literature. Social Service Review, 94(4), 693-747. https://doi.org/10.1086/ 712413

Ayón, Y., Jenson, J. M., Altschul, I., Farrar, J., McQueen, J., Greer, E., Downing, B., \& Simmons, J. (2014). The persistent effect of race and the promise of alternatives to suspension in school discipline outcomes. Children and Youth Services Review, 44, 379-386. https://doi.org/10.1016/j.childyouth.2014.06.025

Banerjee, M., Byrd, C., \& Rowley, S. (2018). The Relationships of School-Based Discrimination and Ethnic-Racial Socialization to African American Adolescents' Achievement Outcomes. Social Sciences, 7(10), 208. MDPI AG. Retrieved from https://doi.org/ 10.3390/socsci7100208

Benner, A. D., \& Kim, S. Y. (2009). Intergenerational experiences of discrimination in Chinese American families: Influences of socialization and stress. Journal of Marriage and Family, 71(4), 862-877. https://doi.org/10.1111/j.1741-3737.2009.00640.x

Bennett, G. G., Merritt, M. M., Sollers, J. J., III., Edwards, C. L., Whitfield, K. E., Brandon, D. T., \& Tucker, R. D. (2004). Stress, coping, and health outcomes among African-Americans: A review of the John Henryism hypothesis. Psychology \& Health, 19(3), 369-383. https://doi.org/10.1080/0887044042000193505

Black, D. S., \& Slavich, G. M. (2016). Mindfulness meditation and the immune system: A systematic review of randomized controlled trials. Annals of the New York Academy of Sciences, 1373(1), 13-24. https://doi.org/10.1111/nyas.12998

Blackmon, S. M., Coyle, L. D., Davenport, S., Owens, A. C., \& Sparrow, C. (2016). Linking racial-ethnic socialization to culture and race-specific coping among African American college students. Journal of Black Psychology, 42(6), 549-576. https://doi.org/10. 1177/0095798415617865 
Brannon, T. N., Higginbotham, G. D., \& Henderson, K. (2017). Class advantages and disadvantages are not so Black and White: Intersectionality impacts rank and selves. Current Opinion in Psychology, 18, 117-122. https://doi.org/10.1016/j.copsyc.2017.08.029

Brody, G. H., Yu, T., Chen, E., Miller, G. E., Kogan, S. M., \& Beach, S. R. H. (2013). Is resilience only skin deep?: Rural African Americans' socioeconomic status-related risk and competence in preadolescence and psychological adjustment and allostatic load at age 19. Psychological Science, 24(7), 1285-1293. https://doi. org/10.1177/0956797612471954

Brody, G. H., Yu, T., Miller, G. E., \& Chen, E. (2016). Resilience in adolescence, health, and psychosocial outcomes. Pediatrics, 138(6), e20161042. https://doi.org/10.1542/peds.2016-1042

Bronfenbrenner, U. (1979). The ecology of human development: Experiments by nature and design. Harvard University Press.

Brown, D. L. (2008). African American resiliency: Examining racial socialization and social support as protective factors. Journal of Black Psychology, 34(1), 32-48. https://doi.org/10.1177/00957 98407310538

Burton, L. (2007). Childhood adultification in economically disadvantaged families: A conceptual model. Family Relations, 56(4), 329-345. https://doi.org/10.1111/j.1741-3729.2007.00463.x

Cave, L., Cooper, M. N., Zubrick, S. R., \& Shepherd, C. C. J. (2020). Racial discrimination and child and adolescent health in longitudinal studies: A systematic review. Social Science and Medicine, 27(250), 112864. https://doi.org/10.1016/j.socscimed.2020. 112864

Ceballo, R., Maurizi, L. K., Suarez, G. A., \& Aretakis, M. T. (2014). Gift and sacrifice: Parental involvement in Latino adolescents' education. Cultural Diversity and Ethnic Minority Psychology, 20(1), 116-127. https://doi.org/10.1037/a0033472

Chan, S. M., Bowes, J., \& Wyver, S. (2009). Parenting style as a context for emotion socialization. Early Education and Development, 20(4), 631-656. https://doi.org/10.1080/10409280802541973

Cheah, C. S. L., Wang, C., Ren, H., Zong, X., Cho, H. S., \& Xue, X. (2020). COVID-19 racism and mental health in Chinese American families. Pediatrics, 146(5), e2020021816. https://doi.org/ 10.1542/peds.2020-021816

Chen, E., Brody, G. H., \& Miller, G. E. (2021a). What are the health consequences of upward mobility? Annual Review of Psychology, 73, 599-628. https://doi.org/10.1146/annur ev-psych-033020-122814

Chen, E., Brody, G. H., Yu, T., Hoffer, L. C., Russak-Pribble, A., \& Miller, G. E. (2021b). Disproportionate school punishment and significant life outcomes: A prospective analysis of Black youths. Psychological Science, 32(9), 1375-1390. https://doi.org/10. 1177/0956797621998308

Cheung, C. S. S., \& Pomerantz, E. M. (2011). Parents' involvement in children's learning in the United States and China: Implications for children's academic and emotional adjustment. Child Development, 82(3), 932-950.

Choi, H., \& Dancy, B. L. (2009). Korean American adolescents' and their parents' perceptions of acculturative stress. Journal of Child and Adolescent Psychiatric Nursing, 22(4), 203-210. https://doi. org/10.1111/j.1744-6171.2009.00200.x

Cokley, K., McClain, S., Enciso, A., \& Martinez, M. (2013). An examination of the impact of minority status stress and impostor feelings on the mental health of diverse ethnic minority college students. Journal of Multicultural Counseling and Development, 41(2), 82-95. https://doi.org/10.1002/j.2161-1912.2013.00029.x

Cole, E. R., \& Omari, S. R. (2003). Race, class and the dilemmas of upward mobility for African Americans. Journal of Social Issues, 59(4), 785-802. https://doi.org/10.1046/j.0022-4537. 2003.00090.x

Cole, P. M., Tamang, B. L., \& Shrestha, S. (2006). Cultural variations in the socialization of young children's anger and shame. Child
Development, 77(5), 1237-1251. https://doi.org/10.1111/j.14678624.2006.00931.x

Colen, C. G., Ramey, D. M., Cooksey, E. C., \& Williams, D. R. (2018). Racial disparities in health among nonpoor African Americans and Hispanics: The role of acute and chronic discrimination. Social Science \& Medicine, 199, 167-180. https://doi.org/10. 1016/j.socscimed.2017.04.051

Coll, C. G., Lamberty, G., Jenkins, R., McAdoo, H. P., Crnic, K., Wasik, B. H., \& Garcia, H. V. (1996). An integrative model for the study of developmental competencies in minority children. Child Development, 67(5), 1891-1914. https://doi.org/10.2307/ 1131600

Coll, C. G., \& Pachter, L. M. (2002). Ethnic and minority parenting. In M. H. Bornstein (Ed.), Handbook of parenting: Social conditions and applied parenting (pp. 1-20). Lawrence Erlbaum Associates Publishers.

Conklin, Q. A., Crosswell, A. D., Saron, C. D., \& Epel, E. S. (2019). Meditation, stress processes, and telomere biology. Current Opinion in Psychology, 28, 92-101. https://doi.org/10.1016/j. copsyc.2018.11.009

Cooper, S. M., \& Smalls, C. (2010). Culturally distinctive and academic socialization: Direct and interactive relationships with African American adolescents' academic adjustment. Journal of Youth Adolescence, 39, 199-212. https://doi.org/10.1007/ s10964-009-9404-1

Cross, F. L., Martinez, S. B. \& Rivas-Drake, D. (2021). Documentation status socialization among Latinx immigrant parents. New Directions for Child and Adolescent Development. Advanced online publication. https://doi.org/10.1002/cad.20420

Cross, F. L., Agi, A., Montoro, J. P., Medina, M. A., Miller-Tejada, S., Pinetta, B. J., Tran-Dubongco, M., \& Rivas-Drake, D. (2020). Illuminating ethnic-racial socialization among undocumented Latinx parents and its implications for adolescent psychosocial functioning. Developmental Psychology, 56(8), 1458-1474. https://doi.org/10.1037/dev0000826

Cunningham, J. (2019). Missing the mark: Standardized testing as epistemological erasure in US schooling. Power and Education, 11(1), 111-120. https://doi.org/10.1177/1757743818812093

Daga, S. S., \& Raval, V. V. (2018). Ethnic-racial socialization, model minority experience, and psychological functioning among south Asian American emerging adults: A preliminary mixed-methods study. Asian American Journal of Psychology, 9(1), 17-31. https://doi.org/10.1037/aap0000108

DeAngelis, R. T. (2020). Striving while Black: Race and the psychophysiology of goal pursuit. Journal of Health and Social Behavior, 61(1), 24-42. https://doi.org/10.1177/0022146520901695

Delgado-Gaitan, C., \& Trueba, H. (1991). Crossing cultural borders. The Falmer Press.

Dich, N., Doan, S. N., \& Evans, G. W. (2017). In risky environments, emotional children have more behavioral problems but lower allostatic load. Health Psychology, 36(5), 468-476. https://doi. org/10.1037/hea0000459

Dich, N., Rozing, M. P., Kivimäki, M., \& Doan, S. N. (2020). Life events, emotions, and immune function: Evidence from Whitehall II cohort study. Behavioral Medicine, 46(2), 153-160. https://doi.org/10.1080/08964289.2019.1570072

Doan, S. N., Dich, N., \& Evans, G. W. (2016). Stress of stoicism: Low emotionality and high control lead to increases in allostatic load. Applied Developmental Science, 20(4), 310-317. https://doi.org/ 10.1080/10888691.2016.1171716

Doan, S. N., Dich, N., Fuller-Rowell, T. E., \& Evans, G. W. (2019). Externalizing behaviors buffer the effects of early life adversity on physiologic dysregulation. Scientific Reports, 9, 13623. https://doi.org/10.1038/s41598-019-49461-x

Doan, S. N., \& Wang, Q. (2010). Maternal discussions of mental states and behaviors: relations to emotion situation knowledge 
in European American and immigrant Chinese children. Child Development, 81(5), 1490-1503. https://doi.org/10.1111/j.14678624.2010.01487.x

Doan, S. N., \& Wang, Q. (2018). Children's emotion knowledge and internalizing problems: The moderating role of culture. Transcultural Psychiatry, 55(5), 689-709. https://doi.org/10.1177/13634 61518792731

Duckworth, A., \& Gross, J. J. (2014). Self-control and grit: Related but separable determinants of success. Current Directions in Psychological Science, 23(5), 319-325. https://doi.org/10.1177/09637 21414541462

Dunbar, A. S., Leerkes, E. M., Coard, S. I., Supple, A. J., \& Calkins, S. (2017). An integrative conceptual model of parental racial/ ethnic and emotion socialization and links to children's socialemotional development among African American families. Child Development Perspectives, 11(1), 16-22.

Dunbar, A. S., Perry, N. B., Cavanaugh, A. M., \& Leerkes, E. M. (2015). African American parents' racial and emotion socialization profiles and young adults' emotional adaptation. Cultural Diversity and Ethnic Minority Psychology, 21(3), 409-419. https://doi.org/10.1037/a0037546

Durik, A. M., Hyde, J. S., Marks, A. C., Roy, A. L., Anaya, D., \& Schultz, G. (2006). Ethnicity and gender stereotypes of emotion. Sex Roles, 54(7), 429-445. https://doi.org/10.1007/ s11199-006-9020-4

Eccles, J. S., Midgley, C., Wigfield, A., Buchanan, C. M., Reuman, D., Flanagan, C., \& MacIver, D. (1993). Development during adolescence: The impact of stage-environment fit on young adolescents' experiences in schools and in families. American Psychologist, 48, 90-101. https://doi.org/10.1037/0003-066X. 48.2.903-066X.48.2.90

Egloff, B., Schmukle, S. C., Burns, L. R., \& Schwerdtfeger, A. (2006). Spontaneous emotion regulation during evaluated speaking tasks: Associations with negative affect, anxiety expression, memory, and physiological responding. Emotion, 6(3), 356-366. https:// doi.org/10.1037/1528-3542.6.3.356

Eisenberg, A. R. (1999). Emotion talk among Mexican American and Anglo American mothers and children from two social classes. Merrill-Palmer Quarterly, 45(2), 267-284.

Eisenberg, N., Cumberland, A., \& Spinrad, T. L. (1998). Parental socialization of emotion. Psychological Inquiry, 9(4), 241-273. https://doi.org/10.1207/s15327965pli0904_1

Eisenberg, N., Fabes, R. A., Murphy, B., Karbon, M., Smith, M., \& Maszk, P. (1996). The relations of children's dispositional empathy-related responding to their emotionality, regulation, and social functioning. Developmental Psychology, 32(2), 195-209. https://doi.org/10.1037/0012-1649.32.2.195

Espinoza, G., Gonzales, N. A., \& Fuligni, A. J. (2016). Parent discrimination predicts Mexican-American adolescent psychological adjustment 1 year later. Child Development, 87(4), 1079-1089. https://doi.org/10.1111/cdev.12521

Evans, A. B., Banerjee, M., Meyer, R., Aldana, A., Foust, M., \& Rowley, S. (2012). Racial socialization as a mechanism for positive development among African American youth. Child Development Perspectives, 6(3), 251-257. https://doi.org/10.1111/j.17508606.2011.00226.x

Ford, D. Y. (1993). Black students' achievement orientation as a function of perceived family achievement orientation and demographic variables. The Journal of Negro Education, 62(1), 47-66. https://doi.org/10.2307/2295399

Fordham, S. (1988). Racelessness as a factor in Black students' school success: Pragmatic strategy or pyrrhic victory? Harvard Educational Review, 58(1), 54-85.

Foxen, P. N. C. of L. R. (2010). Speaking out: Latino youth on discrimination in the United States. http://publications.nclr.org/handle/ $123456789 / 1141 \% 0 \mathrm{~A}$
French, B. H., Lewis, J. A., Mosley, D. V., Adames, H. Y., ChavezDueñas, N. Y., Chen, G. A., \& Neville, H. A. (2020). Toward a psychological framework of radical healing in communities of color. Counseling Psychologist, 48(1), 14-46. https://doi.org/10. 1177/0011000019843506

Friedlmeier, W., Corapci, F., \& Cole, P. M. (2011). Emotion socialization in cross-cultural perspective. Social and Personality Psychology Compass, 5(7), 410-427. https://doi.org/10.1111/j. 1751-9004.2011.00362.x

Fuligni, A. J. (2001). Family obligation and the academic motivation of adolescents from Asian, Latin American, and European backgrounds. New Directions for Child and Adolescent Development, 94, 61-75. https://doi.org/10.1002/cd.31

Fuller-Rowell, T. E., Curtis, D. S., Doan, S. N., \& Coe, C. L. (2015). Racial disparities in the health benefits of educational attainment: A study of inflammatory trajectories among African American and white adults. Psychosomatic Medicine, 77(1), 33-40. https:// doi.org/10.1097/PSY.0000000000000128

Fuller-Rowell, T. E., \& Doan, S. N. (2010). The social costs of academic success across ethnic groups. Child Development, 81(6), 1696-1713. https://doi.org/10.1111/j.1467-8624.2010.01504.x

Fung, H. (1999). Becoming a moral child: The socialization of shame among young Chinese children. Ethos, 27(2), 180-209. https:// doi.org/10.1525/eth.1999.27.2.180

Fung, J., Kim, J. J., Jin, J., Chen, G., Bear, L., \& Lau, A. S. (2019). A randomized trial evaluating school-based mindfulness intervention for ethnic minority youth: Exploring mediators and moderators of intervention effects. Journal of Abnormal Child Psychology, 47(1), 1-19. https://doi.org/10.1007/s10802-018-0425-7

Garrett-Peters, P., Mills-Koonce, R., Zerwas, S., Cox, M., \& VernonFeagans, L. (2011). Fathers' early emotion talk: Associations with income, ethnicity, and family factors. Journal of Marriage and Family, 73(2), 335-353. https://doi.org/10.1111/j.17413737.2010.00810.x

Gartner, M., Kiang, L., \& Supple, A. (2014). Prospective links between ethnic socialization, ethnic and American identity, and well-being among Asian-American adolescents. Journal of Youth and Adolescence, 43(10), 1715-1727. https://doi.org/ 10.1007/s10964-013-0044-0

Geronimus, A. T., \& Thompson, J. P. (2004). To denigrate, ignore, or disrupt: Racial inequality in health and the impact of a policyinduced breakdown of African American communities. $D u$ Bois Review, 1(2), 247-279. https://doi.org/10.1017/S1742 058X04042031

Golden, N. A. (2017). There's still that window that's open" the problem with "grit. Urban Education, 52(3), 343-369. https:// doi.org/10.1177/0042085915613557

Greco, L. A., Baer, R. A., \& Smith, G. T. (2011). Assessing mindfulness in children and adolescents: Development and validation of the Child and Adolescent Mindfulness Measure (CAMM). Psychological Assessment, 23(3), 606-614. https://doi.org/10. 1037/a0022819

Grindal, M., \& Nieri, T. (2015). An examination of ethnic identity and academic performance: Assessing the multidimensional role of parental ethnic-racial socialization among a sample of Latino adolescents. Race and Social Problems, 7(3), 242-255. https://doi.org/10.1007/s12552-015-9154-5

Grusec, J. E., \& Hastings, P. D. (Eds.). (2015). Handbook of socialization, 2nd edition: Theory and research. Guilford Press.

Hajal, N. J., \& Paley, B. (2020). Parental emotion and emotion regulation: A critical target of study for research and intervention to promote child emotion socialization. Developmental Psychology, 56(3), 403-417. https://doi.org/10.1037/dev0000864

Harris, F., III., \& Bensimon, E. M. (2007). The equity scorecard: A collaborative approach to assess and respond to racial/ethnic 
disparities in student outcomes. New Directions for Student Services, 120, 77-84. https://doi.org/10.1002/ss.259

Harwood, R. L., Miller, J. G., \& Irizarry, N. L. (1995). Culture and attachment: Perceptions of the child in context. Guilford Press.

Hayes, A. M., \& Feldman, G. (2004). Clarifying the construct of mindfulness in the context of emotion regulation and the process of change in therapy. Clinical Psychology: Science and Practice, 11(3), 255-262. https://doi.org/10.1093/clipsy. bph080

Hernández, M. M., Conger, R. D., Robins, R. W., Bacher, K. B., \& Widaman, K. F. (2014). Cultural socialization and ethnic pride among Mexican-origin adolescents during the transition to middle school. Child Development, 85(2), 695-708. https://doi.org/ 10.1111/cdev.12167

Higgins, E. T. (1998). Promotion and prevention: Regulatory focus as a motivational principle. In Advances in experimental social psychology (Vol. 30, pp. 1-46). Academic Press.

Higgins, E. T., \& Silberman, I. (1998). Development of regulatory focus: Promotion and prevention as ways of living. In J. Heckhausen \& C. S. Dweck (Eds.), Motivation and self-regulation across the life span (pp. 78-113). Cambridge University Press.

Hill, N. E. (2001). Parenting and academic socialization as they relate to school readiness: The roles of ethnicity and family income. Journal of Educational Psychology, 93(4), 686-697. https://doi. org/10.1037/0022-0663.93.4.686

Hill, N. E., \& Tyson, D. F. (2009). Assessment of the strategies that promote achievement. Developmental Psychology, 45(3), 740763. https://doi.org/10.1037/a0015362.Parental

Hudson, D. L., Neighbors, H. W., Geronimus, A. T., \& Jackson, J. S. (2015). Racial discrimination, John Henryism, and depression among African Americans. Journal of Black Psychology, 42(3), 221-243. https://doi.org/10.1177/0095798414567757

Hughes, D., Rodriguez, J., Smith, E. P., Johnson, D. J., Stevenson, H. C., \& Spicer, P. (2006). Parents' ethnic-racial socialization practices: A review of research and directions for future study. Developmental Psychology, 42(5), 747-770. https://doi.org/10. 1037/0012-1649.42.5.747

Inzlicht, M., Werner, K. M., Briskin, J. L., \& Roberts, B. W. (2021). Integrating models of self-regulation. Annual Review of Psychology, 72, 319-345. https://doi.org/10.1146/annur ev-psych-061020-105721

James, S. A. (1994). John Henryism and the health of African-Americans. Culture, Medicine, and Psychiatry, 18(2), 163-182. https:// doi.org/10.1007/BF01379448

Jones, S. C. T., Anderson, R. E., Gaskin-Wasson, A. L., Sawyer, B. A., Applewhite, K., \& Metzger, I. W. (2020). From "crib to coffin": Navigating coping from racism-related stress throughout the lifespan of Black Americans. American Journal of Orthopsychiatry, 90(2), 267-282. https://doi.org/10.1037/ort0000430

Juang, L. P., \& Cookston, J. T. (2009). A longitudinal study of family obligation and depressive symptoms among Chinese American adolescents. Journal of Family Psychology, 23(3), 396-404. https://doi.org/10.1037/a0015814

Juang, L. P., Shen, Y., Kim, S. Y., \& Wang, Y. (2016). Development of an Asian American parental racial-ethnic socialization scale. Cultural Diversity and Ethnic Minority Psychology, 22(3), 417431. https://doi.org/10.1037/cdp0000083

Kabat-Zinn, J. (2003). Mindfulness-based interventions in context: Past, present, and future. Clinical Psychology: Science and Practice, 10(2), 144-156. https://doi.org/10.1093/clipsy.bpg016

Kim, S. Y., Schwartz, S. J., Perreira, K. M., \& Juang, L. P. (2018). Culture's influence on stressors, parental socialization, and developmental processes in the mental health of children of immigrants. Annual Review of Clinical Psychology, 14, 343-370. https://doi. org/10.1146/annurev-clinpsy-050817-084925
Kramer, L. R. (1991). The social construction of ability perceptions: An ethnographic study of gifted adolescent girls. The Journal of Early Adolescence, 11(3), 340-362. https://doi.org/10.1177/ 0272431691113003

Kyere, E., \& Huguley, J. P. (2020). Exploring the process by which positive racial identity develops and influences academic performance in Black youth: Implications for social work. Journal of Ethnic and Cultural Diversity in Social Work, 29(4), 286-304. https://doi.org/10.1080/15313204.2018.1555502

La Roche, M. J., \& Shriberg, D. (2004). Diversity in consultation: High stakes exams and latino students: toward a culturally sensitive education for Latino children in the United States. Journal of Educational and Psychological Consultation, 15(2), 205-223. https://doi.org/10.1207/s1532768xjepc1502_8

Lambert, S. F., Robinson, W. L., \& Ialongo, N. S. (2014). The role of socially prescribed perfectionism in the link between perceived racial discrimination and african american adolescents' depressive symptoms. Journal of Abnormal Child Psychology, 42(4), 577-587. https://doi.org/10.1007/s10802-013-9814-0

Lambert, S. F., Rose, T., Saleem, F. T., \& Caldwell, C. H. (2021). Ethnic-racial socialization, perceived neighborhood quality, and psychosocial adjustment among African American and Caribbean Black adolescents. Journal of Research on Adolescence, 31(1), 120-138. https://doi.org/10.1111/jora.12586

Lau, A. S., Fung, J., Wang, S.-W., \& Kang, S.-M. (2009). Explaining elevated social anxiety among Asian Americans: Emotional attunement and a cultural double bind. Cultural Diversity and Ethnic Minority Psychology, 15(1), 77-85. https://doi.org/10. 1037/a0012819

Leerkes, E. M., \& Siepak, K. J. (2006). Attachment linked predictors of women's emotional and cognitive responses to infant distress. Attachment \& Human Development, 8(1), 11-32. https://doi.org/ $10.1080 / 14616730600594450$

Lesane-Brown, C. L. (2006). A review of race socialization within Black families. Developmental Review, 26(4), 400-426. https:// doi.org/10.1016/j.dr.2006.02.001

Lindsay, E. K., Chin, B., Greco, C. M., Young, S., Brown, K. W., Wright, A. G. C., Smyth, J. M., Burkett, D., \& Creswell, J. D. (2018). How mindfulness training promotes positive emotions: Dismantling acceptance skills training in two randomized controlled trials. Journal of Personality and Social Psychology, 115(6), 944-973. https://doi.org/10.1037/pspa0000134

Liu, L. L., \& Lau, A. S. (2013). Teaching about race/ethnicity and racism matters: An examination of how perceived ethnic racial socialization processes are associated with depression symptoms. Cultural Diversity and Ethnic Minority Psychology, 19(4), 383394. https://doi.org/10.1037/a0033447

Louie, V. S. (2004). Compelled to excel: Immigration, education, and opportunity among Chinese Americans. Stanford University Press.

Lugo-Candelas, C. I., Harvey, E. A., \& Breaux, R. P. (2015). Emotion socialization practices in Latina and European American mothers of preschoolers with behavior problems. Journal of Family Studies, 21(2), 144-162. https://doi.org/10.1080/13229400.2015. 1020982

Lugo-Candelas, C. I., Harvey, E. A., Breaux, R. P., \& Herbert, S. D. (2016). Ethnic differences in the relation between parental emotion socialization and mental health in emerging adults. Journal of Child and Family Studies, 25(3), 922-938. https://doi.org/10. 1007/s10826-015-0266-8

Luthar, S. S. (2006). Resilience in development: A synthesis of research across five decades.

Luthar, S. S. (1991). Vulnerability and resilience: A study of high-risk adolescents. Child Development, 62(3), 600-616. https://doi.org/ $10.2307 / 1131134$ 
Luthar, S. S., Doernberger, C. H., \& Zigler, E. (1993). Resilience is not a unidimensional construct: Insights from a prospective study of inner-city adolescents. Development and Psychopathology, 5(4), 703-717. https://doi.org/10.1017/S0954579400006246

Luthar, S. S., Ebbert, A. M., \& Kumar, N. L. (2021). Risk and resilience among Asian American youth: Ramifications of discrimination and low authenticity in self-presentations. American Psychologist, 76(4), 643.

McBee, M. (2010). Examining the probability of identification for gifted programs for students in georgia elementary schools: A multilevel path analysis study. Gifted Children Quarterly, 54(4), 283-297. https://doi.org/10.1177/0016986210377927

McCord, B. L., \& Raval, V. V. (2016). Asian Indian immigrant and White American maternal emotion socialization and child socioemotional functioning. Journal of Child and Family Studies, 25, 464-474. https://doi.org/10.1007/s10826-015-0227-2

McKown, C. (2004). Age and ethnic variation in children's thinking about the nature of racism. Journal of Applied Developmental Psychology, 25(5), 597-617. https://doi.org/10.1016/j.appdev. 2004.08.001

Mekawi, Y., Carter, S., Packard, G., Wallace, S., Michopoulos, V., \& Powers, A. (2021). When (passive) acceptance hurts: Race-based coping moderates the association between racial discrimination and mental health outcomes among Black Americans. Theory, Research, Practice, and Policy. Advance online publication. https://doi.org/10.1037/tra0001077

Metz, S. M., Frank, J. L., Reibel, D., Cantrell, T., Sanders, R., \& Broderick, P. C. (2013). The effectiveness of the Learning to BREATHE program on adolescent emotion regulation. Research in Human Development, 10(3), 252-272. https://doi.org/10.1080/ 15427609.2013.818488

Miller, G. E., Yu, T., Chen, E., \& Brody, G. H. (2015). Self-control forecasts better psychosocial outcomes but faster epigenetic aging in low-SES youth. Proceedings of the National Academy of Sciences, 112(33), 10325-10330. https://doi.org/10.1073/pnas. 1505063112

Moffitt, T. E., Arseneault, L., Belsky, D., Dickson, N., Hancox, R. J., Harrington, H. L., Houts, R., Poulton, R., Roberts, B. W., Ross, S., Sears, M. R., Murray Thomson, W., \& Caspi, A. (2011). A gradient of childhood self-control predicts health, wealth, and public safety. Proceedings of the National Academy of Sciences, 108(7), 2693-2698. https://doi.org/10.1073/pnas.1010076108

Montague, D. F., Magai, C., Consedine, N. S., \& Gillespie, M. (2003). Attachment in African American and European American older adults: The roles of early life socialization and religiosity. Attachment \& Human Development, 5(2), 188-214. https://doi.org/10. 1080/1461673031000108487

Moore, S. A., Zoellner, L. A., \& Mollenholt, N. (2008). Are expressive suppression and cognitive reappraisal associated with stressrelated symptoms? Behavior Research and Therapy, 46(9), 9931000. https://doi.org/10.1016/j.brat.2008.05.001

Morris, A., Silk, J. S., Steinberg, L., Myers, S. S., \& Robinson, L. (2007). The role of the family context in the development of emotion regulation. Social Development, 16, 361-388. https:// doi.org/10.1111/j.1467-9507.2007.00389.x

Muenks, K., et al. (2017). How true is grit? Assessing its relations to high school and college students' personality characteristics, self-regulation, engagement, and achievement. Journal of Educational Psychology, 109(5), 99.

Neblett, E. W., Jr., Smalls, C. P., Ford, K. R., Nguyên, H. X., \& Sellers, R. M. (2008). Racial socialization and racial identity: African American parents' messages about race as precursors to identity. Journal of Youth and Adolescence, 38, 189-203. https://doi.org/ 10.1007/s10964-008-9359-7

Nelson, J. A., Leerkes, E. M., O’Brien, M., Calkins, S. D., \& Marcovitch, S. (2012a). African American and European American mothers' beliefs about negative emotions and emotion socialization practices. Parenting Science \& Practice, 12(1), 22-41. https://doi.org/10.1080/15295192.2012.638871

Nelson, J. A., Leerkes, E. M., O’Brien, M., Calkins, S. D., \& Marcovitch, S. (2012b). African American and European American mothers' beliefs about negative emotions and emotion socialization practices. Parenting, 12(1), 22-41.

Nelson, J. A., Leerkes, E. M., Perry, N. B., O’Brien, M., Calkins, S. D., \& Marcovitch, S. (2013). European-American and AfricanAmerican mothers' emotion socialization practices relate differently to their children's academic and social-emotional competence. Social Development, 22(3), 485-498. https://doi.org/10. 1111/j.1467-9507.2012.00673.x

Nguyen, C. P., Wong, Y. J., Juang, L. P., \& Park, I. J. K. (2015). Pathways among Asian Americans' family ethnic socialization, ethnic identity, and psychological well-being: A multigroup mediation model. Asian American Journal of Psychology, 6(3), 273-280. https://doi.org/10.1037/aap0000026

O’Brien, K. M., Tronick, E. Z., \& Moore, C. L. (2013). Relationship between hair cortisol and perceived chronic stress in a diverse sample. Stress and Health, 29(4), 337-344.

Omadeke, J. (2021). Why the model minorty myth is so harmful. Harvard Business Review. Retrieved from https://hbr.org/2021/06/ why-the-model-minority-myth-is-so-harmful https://doi.org/10. $1002 /$ smi.2475

Perry, N., Leerkes, E. M., Dunbar, A. S., \& Cavanaugh, A. M. (2017). Gender and ethnic differences in young adults' emotional reactions to parental punitive and minimizing emotion socialization practices. Emerging Adulthood, 5, 83-92. https://doi.org/10. $1177 / 2167696816653856$

Phinney, J. S., \& Chavira, V. (1995). Parental ethnic socialization and adolescent coping with problems related to ethnicity. Journal of Research on Adolescence, 5(1), 31-53. https://doi.org/10.1207/ s15327795jra0501_2

Pintar Breen, A. I., Tamis-LeMonda, C. S., \& Kahana-Kalman, R. (2018). Latina mothers' emotion socialization and their children's emotion knowledge. Infant and Child Development, 27(3), e2077. https://doi.org/10.1002/icd.2077

Priest, N., Walton, J., White, F., Kowal, E., Baker, A., \& Paradies, Y. (2014). Understanding the complexities of ethnic-racial socialization processes for both minority and majority groups: A 30-year systematic review. International Journal of Intercultural Relations, 43(Part B), 139-155. https://doi.org/10.1016/j. ijintrel.2014.08.003

Quintana, S. M. (1998). Children's developmental understanding of ethnicity and race. Applied and Preventive Psychology, 7(1), $27-45$.

Rank, M. R. (2005). One nation, underprivileged. Oxford University Press.

Raval, V., \& Martini, T. S. (2009). Maternal socialization of children's anger, sadness, and physical pain in two communities in Gujarat, India. International Journal of Behavioral Development, 33(3), 215-229. https://doi.org/10.1177/0165025408098022

Reese, L., Balzano, S., Gallimore, R., \& Goldenberg, C. (1995). The concept of educación: Latino family values and American schooling. International Journal of Educational Research, 23(1), 57-81. https://doi.org/10.1016/0883-0355(95)93535-4

Rivas-Drake, D., \& Marchand, A. (2016). Academic socialization among Latino Families: Exploring the compensatory role of cultural processes. Research in Human Development, 13(3), 225-240. https://doi.org/10.1080/15427609.2016.1194708

Saleem, F. T., \& Lambert, S. F. (2016). Differential effects of racial socialization messages for African American adolescents: Personal versus institutional racial discrimination. Journal of Child and Family Studies, 25(5), 1385-1396. https://doi.org/10.1007/ s10826-015-0326-0 
Sanada, K., Montero-Marin, J., Díez, M. A., Salas-Valero, M., PérezYus, M. C., Morillo, H., Demarzo, M. M. P., García-Toro, M., \& García-Campayo, J. (2016). Effects of mindfulness-based interventions on salivary cortisol in healthy adults: A meta-analytical review. Frontiers in Physiology, 7, 471. https://doi.org/10.3389/ fphys.2016.00471

Seeman, T., Epel, E., Gruenewald, T., Karlamangla, A., \& Mcewen, B. S. (2010). Socioeconomic differentials in peripheral biology: Cumulative allostatic load. Annals of the New York Academy of Sciences, 1186(1), 223-239. https://doi.org/10.1111/j.17496632.2009.05341.x

Seeman, T., Merkin, S. S., Crimmins, E., Koretz, B., Charette, S., \& Karlamangla, A. (2008). Education, income and ethnic differences in cumulative biological risk profiles in a national sample of US adults: NHANES III (1988-1994). Social Science \& Medicine, 66(1), 72-87. https://doi.org/10.1016/j.socscimed. 2007.08 .027

Simon, C. (2021). The role of race and ethnicity in parental ethnicracial socialization: A scoping review of research. Journal of Child and Family Studies, 30, 182-195. https://doi.org/10.1007/ s10826-020-01854-7

Smith, M., \& Walden, T. (2001). An exploration of African American preschool-aged children's behavioral regulation in emotionally arousing situations. Child Study Journal, 31(1), 13-45.

Spencer, M. B., Harpalani, V., Cassidy, E., Jacobs, C. Y., Donde, S., Goss, T. N., Muñoz-Miller, M., Charles, N., \& Wilson, S. (2006). Understanding vulnerability and resilience from a normative developmental perspective: Implications for racially and ethnically diverse youth. In D. Cicchetti \& D. J. Cohen (Eds.), Developmental psychopathology: Theory and method (pp. 627-672). John Wiley \& Sons Inc.

Spera, C., Wentzel, K. R., \& Matto, H. C. (2009). Parental aspirations for their children's educational attainment: Relations to ethnicity, parental education, children's academic performance, and parental perceptions of school climate. Journal of Youth Adolescence, 38, 1140-1152. https://doi.org/10.1007/s10964-008-9314-7

Steele, C. M. (2011). Whistling Vivaldi: How stereotypes affect us and what we can do. WW Norton \& Company.

Suárez-Orozco, C., \& Suárez-Orozco, M. M. (2001). Children of immigration. Harvard University Press.

Suizzo, M. A., Jackson, K. M., Pahlke, E., McClain, S., Marroquin, Y., Blondeau, L. A., \& Hong, K. (2016). Parents' school satisfaction and academic socialization predict adolescents' autonomous motivation: A mixed-method study of low-income ethnic minority families. Journal of Adolescent Research, 31(3), 343-374.

Tao, A., Zhou, Q., \& Wang, Y. (2010). Parental reactions to children's negative emotions: Prospective relations to Chinese children's psychological adjustment. Journal of Family Psychology, 24(2), 135-144. https://doi.org/10.1037/a0018974

Telzer, E. H., \& Fuligni, A. J. (2009). Daily family assistance and the psychological well-being of adolescents from Latin American, Asian, and European backgrounds. Developmental Psychology, 45(4), 1177-1189. https://doi.org/10.1037/a0014728

Telzer, E. H., Gonzales, N., \& Fuligni, A. J. (2014). Family obligation values and family assistance behaviors: Protective and risk factors for Mexican-American adolescents' substance use. Journal of Youth and Adolescence, 43, 270-283. https://doi.org/10.1007/ s10964-013-9941-5

Telzer, E. H., Tsai, K. M., Gonzales, N., \& Fuligni, A. J. (2015). Mexican American adolescents' family obligation values and behaviors: Links to internalizing symptoms across time and context. Developmental Psychology, 51(1), 75-86. https://doi.org/10.1037/a0038 434

Tewell, E. (2020). The problem with grit: Dismantling deficit thinking in library instruction. Portal Libraries and the Academy, 20(1), 137-159.
Thai, C. J., Lyons, H. Z., Lee, M. R., \& Iwasaki, M. (2017). Microaggressions and self-esteem in emerging Asian American adults: The moderating role of racial socialization. Asian American Journal of Psychology, 8(2), 83-93. https://doi.org/10.1037/aap0000079

Tran, A. G. T. T., \& Lee, R. M. (2010). Perceived ethnic-racial socialization, ethnic identity, and social competence among Asian American late adolescents. Cultural Diversity and Ethnic Minority Psychology, 16(2), 169-178. https://doi.org/10.1037/a0016400

Troy, A. S., \& Mauss, I. B. (2011). Resilience in the face of stress: Emotion regulation as a protective factor. In S.M. Southwick, B.T. Litz, D. Charney, \& M.J. Friedman (Eds.), Resilience and mental health: Challenges across the lifespan (30-44). Cambridge University Press. https://doi.org/10.1017/CBO9780511994791.004

Tsai, J. L., Louie, J. Y., Chen, E. E., \& Uchida, Y. (2007). Learning what feelings to desire: Socialization of ideal affect through children's storybooks. Personality and Social Psychology Bulletin, 33(1), 17-30. https://doi.org/10.1177/0146167206292749

Tsai, K. M., Telzer, E. H., Gonzales, N. A., \& Fuligni, A. J. (2015). Parental cultural socialization of Mexican-American adolescents' family obligation values and behaviors. Child Development, 86(4), 1241-1252. https://doi.org/10.1111/cdev.12358

Tsai, W., Nguyen, D. J., Weiss, B., Ngo, V., \& Lau, A. S. (2017). Cultural differences in the reciprocal relations between emotion suppression coping, depressive symptoms and interpersonal functioning among adolescents. Journal of Abnormal Child Psychology, 45(4), 657-669. https://doi.org/10.1007/s10802-016-0192-2

Umaña-Taylor, A. J., \& Hill, N. E. (2020). Ethnic-racial socialization in the family: A decade's advance on precursors and outcomes. Journal of Marriage and Family, 82(1), 244-271. https://doi.org/ 10.1111 jomf.12622

Umaña-Taylor, A. J., O'donnell, Knight, M. G. P., Roosa, M. W., Berkel, C., \& Nair, R. (2014). Mexican-origin early adolescents' ethnic socialization, ethnic identity, and psychosocial functioning. The Counseling Psychologist, 42(2), 170-200. https://doi.org/10.1177/ 0011000013477903

Waldfogel, J. (2006). What children need. Harvard University Press.

Wang, M. T., \& Peck, S. C. (2013). Adolescent educational success and mental health vary across school engagement profiles. Developmental Psychology, 49(7), 1266-1276. https://doi.org/10.1037/ a0030028

Wang, M.-T., \& Sheikh-Khalil, S. (2014). Does parental involvement matter for student achievement and mental health in high school? Child Development, 85(2), 610-625. https://doi.org/10.1111/cdev.12153

Wang, M.-T., Smith, L. V., Miller-Cotto, D., \& Huguley, J. P. (2020). Parental ethnic-racial socialization and children of color's academic success: A meta-analytic review. Child Development, 91(3), e528e544. https://doi.org/10.1111/cdev.13254

Weis, L., \& Fine, M. (2012). Critical bifocality and circuits of privilege: Expanding critical ethnographic theory and design. Harvard Educational Review, 82(2), 173-201.

Wilkins, N. J., \& Kuperminc, G. P. (2010). Why try? Achievement motivation and perceived academic climate among Latino youth. The Journal of Early Adolescence, 30(2), 246-276. https://doi.org/10. 1177/0272431609333303

Williams, D. R., Priest, N., \& Anderson, N. B. (2016). Understanding associations among race, socioeconomic status, and health: Patterns and prospects. Health Psychology, 35(4), 407-411. https:// doi.org/10.1037/hea0000242

Woo, B., Maglalang, D. D., Ko, S., Park, M., Choi, Y., \& Takeuchi, D. T. (2020). Racial discrimination, ethnic-racial socialization, and cultural identities among Asian American youths. Cultural Diversity and Ethnic Minority Psychology, 26(4), 447-459. https://doi.org/ $10.1037 / \mathrm{cdp} 0000327$

Xie, M., Fowle, J., Ip, P. S., Haskin, M., \& Yip, T. (2021). Profiles of ethnic-racial identity, socialization, and model minority experiences: Associations with well-being among Asian American adolescents. 
Journal of Youth and Adolescence, 50(6), 1173-1188. https://doi. org/10.1007/s10964-021-01436-w

Yamamoto, Y., \& Holloway, S. D. (2010). Parental expectations and children's academic performance in sociocultural context. Educational Psychology Review, 22(3), 189-214. https://doi.org/10.1007/ s10648-010-9121-z

Yang, S., \& Rettig, K. D. (2003). The value tensions in Korean-American mother-child relationships while facilitating academic success. Personal Relationships, 10(3), 349-369. https://doi.org/10.1111/ 1475-6811.00054

Yang, Y., Song, Q., Doan, S. N., \& Wang, Q. (2020). Maternal reactions to children's negative emotions: Relations to children's socioemotional development among European American and Chinese immigrant children. Transcultural Psychiatry., 57(3), 408-420. https://doi.org/10.1177/1363461520905997

Yoo, H. C., Burrola, K. S., \& Steger, M. F. (2010). A preliminary report on a new measure: Internalization of the Model Minority Myth
Measure (IM-4) and its psychological correlates among Asian American college students. Journal of Counseling Psychology, 57(1), 114-127. https://doi.org/10.1037/a0017871

Yoo, H. C., Miller, M. J., \& Yip, P. (2015). Validation of the internalization of the Model Minority Myth Measure (IM-4) and its link to academic performance and psychological adjustment among Asian American adolescents. Cultural Diversity and Ethnic Minority Psychology, 21(2), 237-246. https://doi.org/10.1037/a0037648

Publisher's Note Springer Nature remains neutral with regard to jurisdictional claims in published maps and institutional affiliations. 